\title{
Value of Pulsed Tissue Doppler Imaging in Predicting the Presence of Significant Coronary Artery Insufficiency
}

\author{
Hossam Eldin M. Mahmoud ${ }^{*}$, Ahlam M. Sabra1 ${ }^{1}$, Mohammad Shafiq Awad², Ahmed Hussein ${ }^{3}$ \\ ${ }^{1}$ Internal Medicine Department, Faculty of Medicine, South Valley University, Qena, Egypt \\ ${ }^{2}$ Cardiology Department, Faculty of Medicine, Beni Suef University, Beni Suef, Egypt \\ ${ }^{3}$ Internal Medicine Department, Faculty of Medicine, Sohag University, Sohag, Egypt \\ Email: *dr_hossam_ismail@yahoo.com
}

How to cite this paper: Mahmoud, H.E.M., Sabra, A.M., Awad, M.S. and Hussein, A. (2020) Value of Pulsed Tissue Doppler Imaging in Predicting the Presence of Significant Coronary Artery Insufficiency. World Journal of Cardiovascular Diseases, 10, 305-312.

https://doi.org/10.4236/wjcd.2020.105028

Received: April 15, 2020

Accepted: May 10, 2020

Published: May 13, 2020

Copyright $\odot 2020$ by author(s) and Scientific Research Publishing Inc. This work is licensed under the Creative Commons Attribution International License (CC BY 4.0).

http://creativecommons.org/licenses/by/4.0/

\section{(c) (i) Open Access}

\begin{abstract}
Background: Coronary artery disease (CAD) is a paramount cause of death. Global and regional left ventricular (LV) systolic function is an important non-invasive marker of CAD. We can use tissue Doppler imaging (TDI) to measure the low velocities generated by myocardium which are: $S^{\prime}$-wave, $E^{\prime}$-wave, and $A^{\prime}$-wave. We aimed to examine the value of the $S^{\prime}$-wave dispersion of TDI across mitral valve annular velocities to predict angiographically significant coronary artery obstruction. Patients and Methods: We included 100 patients with symptoms suggesting CAD. All patients had undergone full history taken and clinical examination; ECG, echocardiographic with assessment of LV function, and Doppler derived mitral valve velocities; TDI with measuring of S'-wave and coronary angiography. Lesions with $\geq 70 \%$ or more stenosis in major epicardial artery or $\geq 50 \%$ stenosis in the left main coronary artery were considered significant. Patients were classified into two groups according to the presence or absence of significant coronary stenosis. Results: Clinical and conventional echocardiographic and Tissue Doppler measures were comparable between the two groups; there was statistically significant difference between Group I and Group II (P value $<0.0001$ ); patients with significant coronary arteries lesions have higher $\mathrm{S}^{\prime}$ wave dispersion as compared with patients with normal or mild significant coronary lesions. Conclusion: S'-wave dispersion may consider a good predictor of angiographically significant coronary artery disease.
\end{abstract}

\section{Keywords}

Tissue Doppler Imaging, TDI, CAD, Mitral Annular Velocities, S'-Wave Dispersion, Coronary Artery Disease, Coronary Angiography 


\section{Introduction}

Ischemic heart disease (IHD) is a major cause of death in developed countries. Although IHD mortality rates worldwide have declined over the past four decades, coronary artery disease (CAD) is still responsible for around $35 \%$ of the overall mortality among individuals over age 35 [1]-[6].

It has been appraised that about $50 \%$ of middle-aged men and $1 / 3$ of middle-aged women in the USA will develop some manifestations of CAD [7].

Non-invasive imaging modalities as stress echocardiography and myocardial perfusion imaging are important and useful tools in everyday practice for early detection, evaluation, and risk stratification of CAD [8]. Global ejection fraction and segmental wall motion abnormalities of left ventricular (LV) are an important marker of CAD in echocardiographic studies, which is usually assessed using two-dimensional echocardiography [9].

Tissue Doppler imaging (TDI) is an echocardiographic modality that uses Doppler principles to measure myocardial motion velocity, Doppler echocardiography relies on changes in frequency of US signals reflected from moving structure [10] [11]. Pulsed-wave TDI is used to calculate the peak myocardial velocities and is primarily the long-axis ventricular motion because of the longitudinally oriented endocardial fibers, which are more parallel to the US waves in the apical views. As the apex remains more or less stationary throughout the cardiac cycle, mitral annular motion is by far a good measure of the overall longitudinal left ventricular (LV) movement [12]. The PW-TDI enables the examiner to obtain several indices, with both clinical and prognostic implications.

\section{Patients and Methods}

This study included 100 patients that calculated by sample size equation (using confidence level, margin of error \& population size) with symptoms suggesting CAD in whom coronary angiography we indicated according to the ACC/AHA Guidelines for the diagnosis and management of patients with stable ischemic heart disease [13] in Qena University Hospital S.V.U. in the period from June 2017 to May 2018 and we excluded patients with previous myocardial infarction (MI), atrial fibrillation (AF), congestive heart failure and significant valvular lesions (more than mild regurgitation or stenosis.

\section{Methodology}

We did all the following for all participants: full medical history, clinical examination, 12 lead ECG, echocardiography and Doppler study performed by GE Vivid S5 Cardiovascular Ultrasound Machine in the form of:

- Two-dimensional Guided M-mode measurements of left ventricular end-diastolic dimension (LVEDD), left ventricular end-systolic dimension (LVESD), ejection fraction (EF) and fraction of shortening (FS) [14].

- Doppler across MV flow velocity waves; E-wave, A-wave, and E/A ratio [14].

- TDI: myocardial velocities of MV annulus were measured for all cases at api- 
cal 4-chamber and apical 2-chamber views. The velocities were measured at the anterior, lateral, septal and inferior walls of MV annulus.

Three velocities were taken for every wall, $S^{\prime}$-wave for systole, E'-wave at early filling phase during early diastole, and $\mathrm{A}^{\prime}$-wave for atrial contraction phase at the end of the ventricular diastole [15] (Figures 1-4), S'-wave dispersion calculated for every patient according to the following formula:

$\mathrm{S}^{\prime}$-wave dispersion $=($ Maximum S' - Minimum S')/Maximum S' \%)

- Coronary angiography: Coronary angiography was done to all patients. The coronary artery obstruction estimated by an expert angiographer and expressed as percentage. Lesions with $\geq 70 \%$ stenosis in major epicardial artery or $\geq 50 \%$ stenosis in the left main coronary artery will consider significant angiographic stenosis [16].

- According to the presence or absence of significant coronary artery (CA) obstruction, patients classified into two groups:

- Group I: Patients with significant CA lesion(s).

- Group II: Patients with normal or with non-significant CA lesion(s).

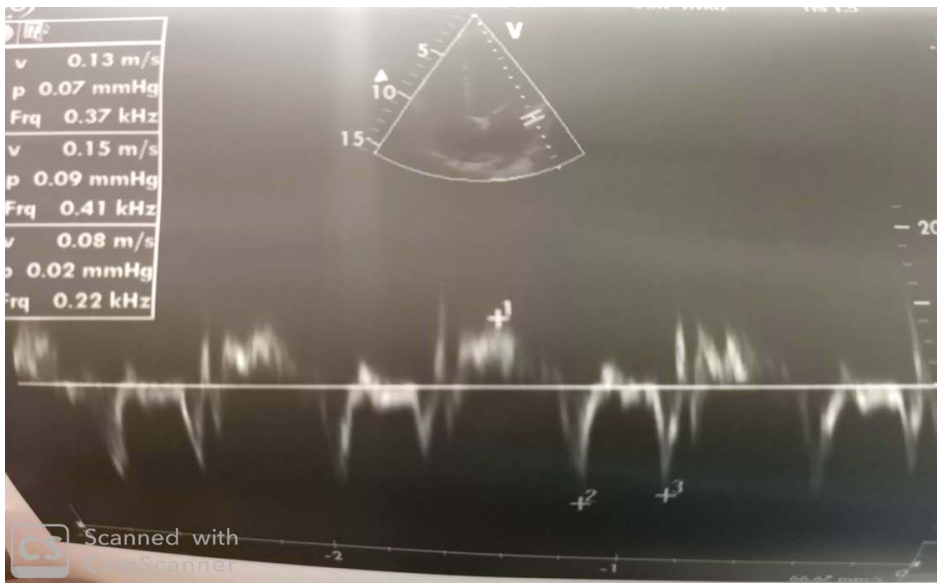

Figure 1. Across lateral wall of MV annulus, $\mathrm{S}^{\prime}$-wave: $0.08 \mathrm{~m} / \mathrm{s}$. E'-wave: $0.15 \mathrm{~m} / \mathrm{s}, \mathrm{A}^{\prime}$-wave: $0.13 \mathrm{~m} / \mathrm{s}$.

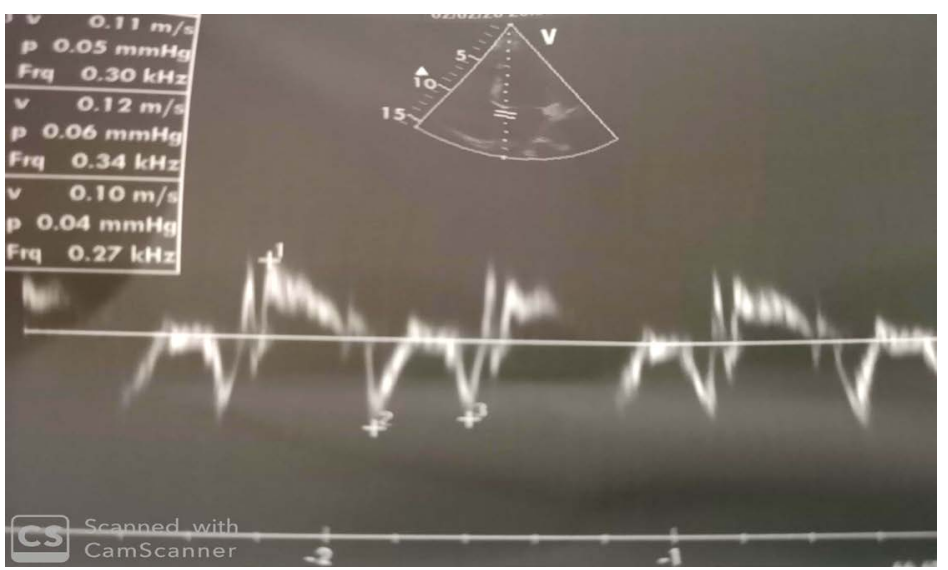

Figure 2. Across septal wall of MV annulus, $\mathrm{S}^{\prime}$-wave: $0.10 \mathrm{~m} / \mathrm{s}$. E'-wave: $0.12 \mathrm{~m} / \mathrm{s}, \mathrm{A}^{\prime}$-wave: $0.11 \mathrm{~m} / \mathrm{s}$. 


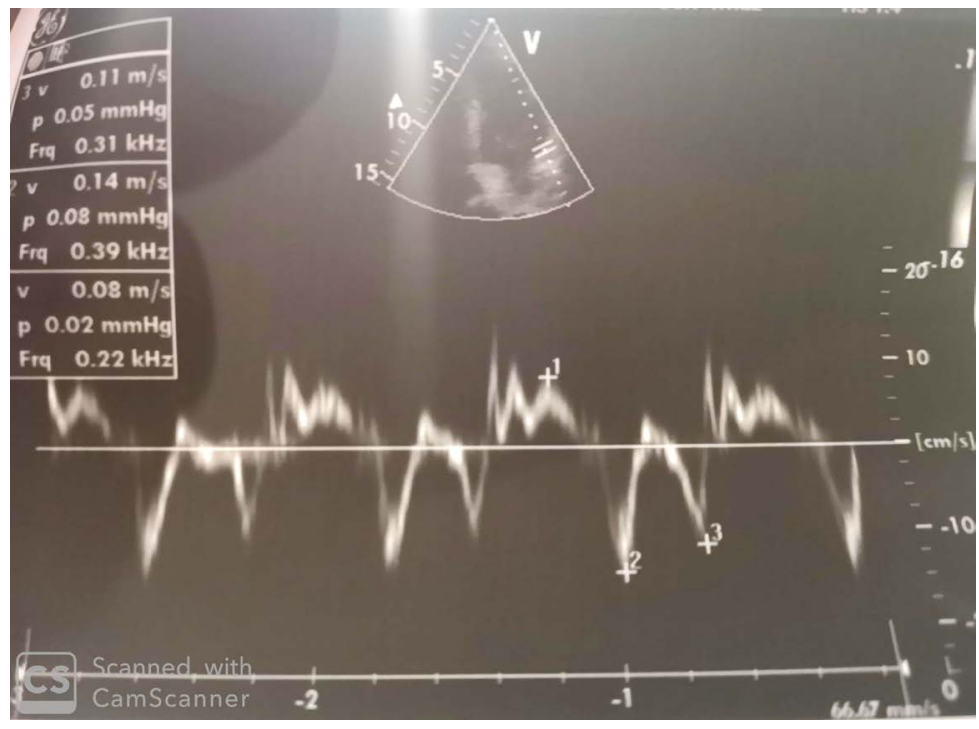

Figure 3. Across anterior wall of MV annulus, $\mathrm{S}^{\prime}$-wave: $0.08 \mathrm{~m} / \mathrm{s}$. E'-wave: $0.14 \mathrm{~m} / \mathrm{s}, \mathrm{A}^{\prime}$-wave: $0.11 \mathrm{~m} / \mathrm{s}$.

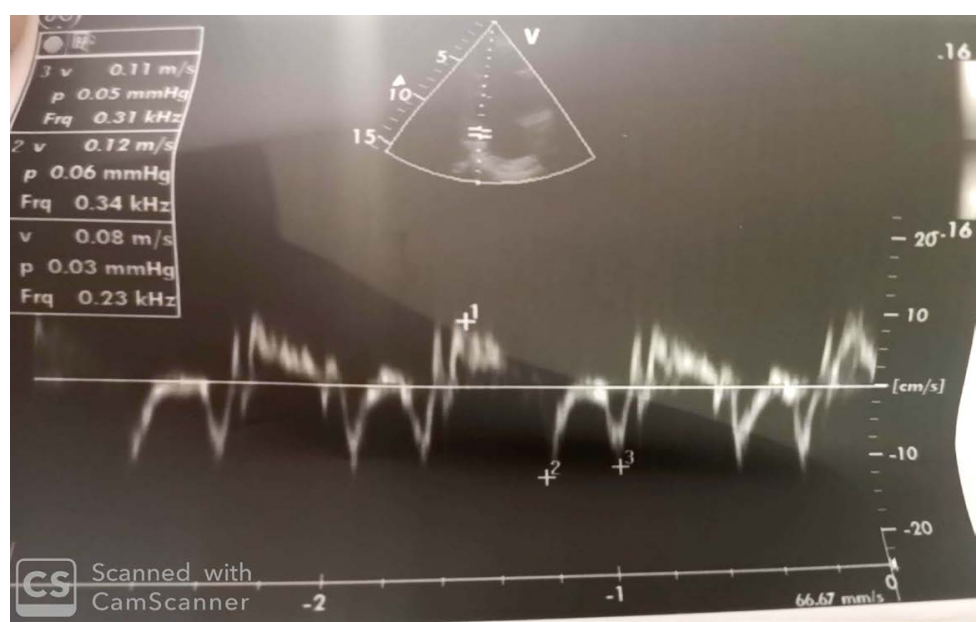

Figure 4. Across inferior wall of MV annulus, $\mathrm{S}^{\prime}$-wave: $0.08 \mathrm{~m} / \mathrm{s}$. E'-wave: $0.12 \mathrm{~m} / \mathrm{s}, \mathrm{A}^{\prime}$-wave: $0.11 \mathrm{~m} / \mathrm{s}$.

\section{Statistical Analysis}

All patients had been analyzed using the Statistical Package for Social Sciences (SPSS) version 25(IBM corporation, Chicago, USA, 2017). Quantitative data was expressed as mean and standard deviation, while qualitative data was expressed as number and percentages. Pearson Correlation coefficient was used to estimate the correlation between two quantitative variables.

\section{Ethics}

Written consents from patients who participated in the study or from their families were obtained and approved by Qena Medical Ethics Committee (QMEC) of Faculty of Medicine-South Valley University. The study was conducted in accordance with the Declaration of Helsinki. 


\section{Results}

Our study included 100 patients with symptoms suggesting CAD in whom coronary angiography was indicated according to the ACC/AHA Guidelines divided into two groups according to the lesions in the coronary angiography (CA):

- Group I normal or mild lesions in CA include 46 patients 24 males and 22 females with mean age $53.91 \pm 6.025$ and

- Group II Significant lesions in CA include 54 patients 27 males and 27 females with mean age $57.43 \pm 8.433$

As shown in Table 1 there was statistically significant difference between the studied groups concerning Age, symptoms, smoking, diabetes mellitus, Ejection fraction and $\mathrm{S}^{\prime}$ wave dispersion.

Patients with significant CAD had a significantly higher $S^{\prime}$ wave dispersion than patients without significant $\mathrm{CAD}(\mathrm{P}$ value $<0.0001)$.

There was no statistically significant difference between the studied groups concerning sex, hypertension and diastolic dysfunction.

\section{Discussion}

TDI is a technique developed for quantification of left ventricular functions; both regional and global, both systolic and diastolic. During ischemic events, the first affected fibers are usually the longitudinal endocardial fibers; thus the velocity changes can be detected from the apical approach. In addition to the systolic S' wave, also the diastolic velocity E' and E'/A' ratio were found to be linking with wall motion abnormalities [17].

The study of Derumeaux et al. [18] found a strong significant correlation between myocardial $S^{\prime}$ wave and regional myocardial blood flow in animal models of myocardial ischemia.

Despite its great value; TDI still has some important limitations. One of these is the lack of clear, well-defined, cutoff values for maximum systolic and diastolic velocities that may suspect CAD [19].

Table 1. Population characteristics, risk factors and echocardiographic data.

\begin{tabular}{cccc}
\hline Variables & $\begin{array}{c}\text { Significant CAD } \\
(\mathbf{n}=\mathbf{5 4})\end{array}$ & $\begin{array}{c}\text { Non-Significant CAD } \\
(\mathbf{n}=\mathbf{4 6})\end{array}$ & P Value \\
\hline Age (ys) & $57.43 \pm 8.433$ & $53.91 \pm 6.025$ & 0.042 \\
Sex (Male, Female) & $24(52.17), 22(47.83 \%)$ & $27(50 \%), 27(50 \%)$ & 0.494 \\
Symptoms & $3(5.56 \%)$, & $17(36.96 \%)$, & 0.0001 \\
(dyspnea, chest pain) & $51(94.44 \%)$ & $29(63.04 \%)$ & 0.047 \\
Smoking & $17(31.48 \%)$ & $7(15.22 \%)$ & 0.001 \\
Diabetes & $34(62.96 \%)$ & $13(28.26 \%)$ & 0.647 \\
Hypertension & $40(74.07 \%)$ & $36(75.26 \%)$ & 0.003 \\
EF (\%) & $57.94 \pm 6.196$ & $61.57 \pm 5.488$ & 0.547 \\
Diastolic dysfunction & $1.2 \pm 0.528$ & $1.13 \pm 0.582$ & 0.0001 \\
S' wave dispersion & $0.386 \pm 0.0767$ & $0.2008 \pm 0.0432$ & \\
\hline
\end{tabular}


This may occur because most of the echocardiographers depend on measuring the systolic and diastolic velocities of the examined segments only. However, this is dependent on the global LV function (both systolic and diastolic) and the latter may be affected by many other systemic diseases such as diabetes mellitus (DM) [20].

However, the American Society of Echocardiography/European Association of Echocardiography guidelines recommended the use of TDI in diagnosis and evaluation of CAD patients; in spite of this important limitation [21].

Our study demonstrated that patients with typical chest pain had significant lesions in coronary angiography as compared with patients complaining of dyspnea (P value 0.0001).

Our study demonstrated that smoker patients had significant lesions in coronary angiography as compared with the non-smoker patients ( $\mathrm{P}$ value 0.047 ) against the study of Al-Daydamony et al. [22].

Our study demonstrated that diabetic patients had significant lesions in coronary angiography as compared with the non-diabetic patients ( $P$ value 0.001 ) against the study of Al-Daydamony et al. [22].

Our study demonstrated that there was no statistical significance difference between Group I and Group II according to hypertension of the studied patients ( $\mathrm{P}$ value 0.647 ) as in Al-Daydamony et al. [22].

Our study demonstrated that patients with lower EF had significant lesions in coronary angiography as compared with the patients with higher EF ( $P$ value 0.003 ) as in Nagib et al. study [23].

Also, our study demonstrated that patients with significant coronary lesions had higher S' wave dispersion as compared with patients with normal or mild significant coronary lesions p-value $<0.0001$ as in Al-Daydamony et al. [22] and Nagib et al. [23] studies; but not applied in multivessel disease.

So our results suggest that TDI has a role in the evaluation of CAD severity same result in Agarwal et al. [19], Al-Daydamony et al. [22] and Nagib et al. [23] studies.

\section{Conclusions}

$\mathrm{S}^{\prime}$-wave dispersion may be useful as a valuable predictor of angiographically significant CAD.

Patients with significant coronary lesions had higher $S^{\prime}$ wave dispersion as compared with patients with normal or mild significant coronary lesions.

\section{Study Limitations}

In addition to the relatively small number of patients and being a single center study, the major limitation of our study is that it did not include many patients' categories like those with previous MI, those with AF and those with CHF. We did not include them due to the effect of MI on LV regional functions beyond the flow limiting coronary obstruction and the inconsistency of TDI velocities 
with AF.

Further studies on a larger number of patients and on other patients' categories are recommended.

\section{Conflicts of Interest}

The authors declare no conflicts of interest regarding the publication of this paper.

\section{References}

[1] Lloyd-Jones, D., Adams, R., Carnethon, M., De Simone, G., Ferguson, T.B., Flegal, K., et al. (2009) Heart Disease and Stroke Statistics-2009 Update: A Report from the American Heart Association Statistics Committee and Stroke Statistics Subcommittee. Circulation, 119, 480-486. https://doi.org/10.1161/CIRCULATIONAHA.108.191259

[2] Rosamond, W., Flegal, K., Furie, K., Go, A., Greenlund, K., Haase, N., et al. (2008) Heart Disease and Stroke Statistics-2008 Update: A Report from the American Heart Association Statistics Committee and Stroke Statistics Subcommittee. Circulation, 117, e25-e146. https://doi.org/10.1161/CIRCULATIONAHA.107.187998

[3] Mozaffarian, D., Benjamin, E.J., Go, A.S., Arnett, D.K., Blaha, M.J., et al. (2016) Executive Summary: Heart Disease and Stroke Statistics-2016 Update: A Report from the American Heart Association. Circulation, 133, 447-454.

[4] Lloyd-Jones, D., Adams, R.J., Brown, T.M., Carnethon, M., Dai, S., De Simone, G., et al. (2010) Executive Summary: Heart Disease and Stroke Statistics-2010 Update: A Report from the American Heart Association. Circulation, 121, 948-954. https://doi.org/10.1161/CIRCULATIONAHA.109.192666

[5] Nicholas, M., Townsend, N., Scarborough, P. and Rayner, M. (2015) Corrigendum to: Cardiovascular Disease in Europe 2014: Epidemiological Update. European Heart Journal, 36, 794. https://doi.org/10.1093/eurheartj/ehu489

[6] Nichols, M., Townsend, N., Scarborough, P. and Rayner, M. (2014) Cardiovascular Disease in Europe 2014: Epidemiological Update. European Heart Journal, 35, 2929. https://doi.org/10.1093/eurheartj/ehu299

[7] Lloyd-Jones, D.M., Larson, M.G., Beiser, A. and Levy, D. (1999) Lifetime Risk of Developing Coronary Heart Disease. Lancet, 353, 89-92. https://doi.org/10.1016/S0140-6736(98)10279-9

[8] Eltzschig, H.K. and Ehlers, R. (2001) Noninvasive Tests in Patients with Stable Coronary Artery Disease. The New England Journal of Medicine, 345, 1351. https://doi.org/10.1056/NEJM200111013451817

[9] Oh, J.K., Appleton, C.P., Hatle, L.K., Nishimura, R.A., Seward, J.B. and Tajik, A.J. (1997) The Noninvasive Assessment of Left Ventricular Diastolic Function with Two-Dimensional and Doppler Echocardiography. Journal of the American Society of Echocardiography, 10, 246-270. https://doi.org/10.1016/S0894-7317(97)70062-2

[10] Negri, F., Sala, C., Valerio, C., Mancia, G. and Cuspidi, C. (2011) Role of Tissue Doppler Imaging for Detection of Diastolic Dysfunction in the Elderly: A Study in Clinical Practice. High Blood Pressure \& Cardiovascular Prevention, 18, 187-193. https://doi.org/10.2165/11593610-000000000-00000

[11] Correale, M., Totaro, A., Ieva, R., Brunetti, N.D. and Di Biase, M. (2011) Time Intervals and Myocardial Performance Index by Tissue Doppler Imaging. Internal and Emergency Medicine, 6, 393-402. https://doi.org/10.1007/s11739-010-0469-3 
[12] Vinereanu, D., Khokhar, A. and Fraser, A.G. (1999) Reproducibility of Pulsed Wave Tissue Doppler Echocardiography. Journal of the American Society of Echocardiography, 12, 492-499. https://doi.org/10.1016/S0894-7317(99)70086-6

[13] Fihn, S.D., Gardin, J.M., Abrams, J., Berra, K., Blankenship, J.C., Dallas, A.P., et al. (2012) 2012 ACCF/AHA/ACP/AATS/PCNA/SCAI/STS Guideline for the Diagnosis and Management of Patients with Stable Ischemic Heart Disease: A Report of the American College of Cardiology Foundation/American Heart Association Task Force on Practice Guidelines, and the American College of Physicians, American Association for Thoracic Surgery, Preventive Cardiovascular Nurses Association, Society for Cardiovascular Angiography and Interventions, and Society of Thoracic Surgeons. Journal of the American College of Cardiology, 60, e44-e164. https://doi.org/10.1161/CIR.0b013e318277d6a0

[14] Mohamed, A.A., Fatma Hassan, M., Hossam, M.I. and Mustafa, M.A. (2018) Value of Pulsed Tissue Doppler Imaging in Predicting the Presence of Significant Coronary Artery Insufficiency.

[15] Ho, C.Y. and Solomon, S.D. (2006) A Clinician's Guide to Tissue Doppler Imaging. Circulation, 113, e396-e398. https://doi.org/10.1161/CIRCULATIONAHA.105.579268

[16] Al-Hijji, M.A., Lennon, R.J., Gulati, R., El Sabbagh, A., Park, J.Y., Crusan, D., et al. (2019) Safety and Risk of Major Complications with Diagnostic Cardiac Catheterization. Circulation: Cardiovascular Interventions, 12, e007791. https://doi.org/10.1161/CIRCINTERVENTIONS.119.007791

[17] Giatrakos, N., Kinali, M., Stephens, D., Dawson, D., Muntoni, F. and Nihoyannopoulos, P. (2006) Cardiac Tissue Velocities and Strain Rate in the Early Detection of Myocardial Dysfunction of Asymptomatic Boys with Duchenne's Muscular Dystrophy: Relationship to Clinical Outcome. Heart, 92, 840-842.

https://doi.org/10.1136/hrt.2005.067710

[18] Derumeaux, G., Ovize, M., Loufoua, J., Andre-Fouet, X., Minaire, Y., Cribier, A., et al. (1998) Doppler Tissue Imaging Quantitates Regional Wall Motion during Myocardial Ischemia and Reperfusion. Circulation, 97, 1970-1977. https://doi.org/10.1161/01.CIR.97.19.1970

[19] Agarwal, R., Gosain, P., Kirkpatrick, J.N., Alyousef, T., Doukky, R., Singh, G., et al. (2012) Tissue Doppler Imaging for Diagnosis of Coronary Artery Disease: A Systematic Review and Meta-Analysis. Cardiovascular Ultrasound, 10, 47. https://doi.org/10.1186/1476-7120-10-47

[20] Murarka, S. and Movahed, M.R. (2010) Diabetic Cardiomyopathy. J Card Fail, 16, 971-979. https://doi.org/10.1016/j.cardfail.2010.07.249

[21] Mor-Avi, V., Lang, R.M., Badano, L.P., Belohlavek, M., Cardim, N.M., Derumeaux, G., et al. (2011) Current and Evolving Echocardiographic Techniques for the Quantitative Evaluation of Cardiac Mechanics: ASE/EAE Consensus Statement on Methodology and Indications Endorsed by the Japanese Society of Echocardiography. European Journal of Echocardiography, 12, 167-205. https://doi.org/10.1093/ejechocard/jer021

[22] Al-Daydamony, M. and Mustafa, T. (2016) Value of S'-Wave Dispersion of Mitral Annular Tissue Velocity in Predicting the Presence of Significant Coronary Artery Stenosis. International Journal of Science and Research, 5, 1409-1413.

[23] Nagib, M., Marghany, K., Abd-El-Hady, M. and Khairy, A. (2018) Correlation between S'-Wave Dispersion of Mitral Annular Tissue Velocity and Severity of Coronary Artery Disease Assessed by SYNTAX Score. The Medical Journal of Cairo University, 86, 91-96. https://doi.org/10.21608/mjcu.2018.55039 